\title{
Análisis comparativo de los diseños institucionales que regulan la participación de las víctimas en Colombia: antes y después de la Ley 1448 de $2012^{*}$
}

\author{
Comparative analysis of the institutional designs that regulate the \\ participation of victims in Colombia: before and after law 1448 of 2012 \\ Análise comparativa dos modelos institucionais que regulam a participação \\ das vítimas na Colômbia: antes e depois da lei 1448 de 2012
}

\author{
JENNIFFER VARGAS REINA \\ Universidad Nacional de Colombia
}

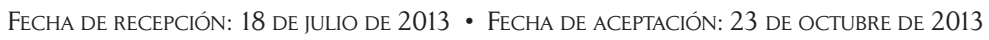

Doi: dx.doi.org/10.12804/esj16.1.2014.04

Para citar este artículo: Vargas Reina, J. (2014). Análisis comparativo de los diseños institucionales que regulan la participación de las víctimas en Colombia: antes y después de la Ley 1448 de 2012. Estudios Socio-Jurídicos, 16(1), $167-207$. doi: dx.doi.org/10.12804/esj16.1.2014.04

\section{RESUMEN}

En este artículo se hace un análisis comparativo de los diseños institucionales que regulan la participación de las víctimas en Colombia antes y después de la Ley 1448 de 2012, con el fin de identificar factores que limitan la incidencia que estos ciudadanos buscan tener en escenarios institucionales de participación creados por el Estado. Concluyo que, si bien con esta ley se introducen reglas de juego para hacer de la participación de las víctimas un proceso más incluyente y democrático, persisten determinados diseños de política pública que hacen de esta un ejercicio separado de las instancias de decisión en lo programático y lo presupuestal, con enormes abismos de articulación entre el complejo y disperso entramado institucional encargado de atender y reparar a las víctimas, y que generan nuevos problemas de acción colectiva. Lo anterior, sumado a la incapacidad estatal de garantizar la seguridad de las víctimas y de sus líderes en lo local, dificulta a todas luces su incidencia en escenarios de toma

* Este artículo presenta resultados de investigación del proyecto desarrollado por el grupo Conflicto e instituciones en una perspectiva comparada en el marco del programa Observatorio de restitución y regulación de derechos de propiedad agraria financiado por Colciencias.

** Mágister en Estudios Políticos de la Universidad Nacional de Colombia, Trabajadora Social de la Universidad de la Salle. Investigadora del grupo Conflicto e instituciones en una perspectiva comparada del Instituto de Estudios Políticos y Relaciones Internacionales IEPRI de la Universidad Nacional de Colombia. Correo electrónico: jenniffervr@gmail.com 
de decisiones y establece enormes retos que debería tener en cuenta el Estado colombiano para replantear diseños de política y garantizar una participación efectiva.

Palabras clave: Participación, víctimas, incidencia política, diseños institucionales.

\section{ABSTRACT}

This article makes a comparative analysis of the institutional designs that regulate the participation of victims in Colombia before and after law 1448 of 2012, in order to identify factors that limit the influence these citizens aim to achieve in the participative scenarios created by the State. I conclude that while this law has introduced rules to make the participation of victims a more inclusive and democratic process, certain elements of the overall policy structure remain that keep it separated from the programmatic and budgetary decision-making aspects, with enormous gaps in coordination between the complex and disperse institutional frameworks responsible for assisting and providing reparations to the victims, and which generate new problems of collective action. This, added to the state's inability to ensure the safety of the victims and their local leaders, greatly hinders the capacity of the Law to affect decision-making and creates enormous challenges that should be taken into account by the Colombian State in order to redesign policy and ensure effective participation.

Key Words: Participation, advocacy, victims, institutional designs.

\section{RESUMO}

Neste artigo se faz uma análise comparativa dos modelos institucionais que regulam a participação das vítimas na Colômbia antes e depois da lei 1448 de 2012, com o fim de identificar fatores que limitam a incidência que estes cidadãos buscam ter em cenários institucionais de participação criados pelo Estado. Concluo que se bem com esta lei introduzem-se regras de jogo para fazer da participação das vítimas um processo mais inclusivo e democrático, persistem determinados modelos de política pública que fazem desta um exercício separado das instâncias de decisão no programático e o orçamentário, com enormes abismos de articulação entre a complexa e dispersa rede institucional encarregada de atender e reparar às vítimas e que geram novos problemas de ação coletiva. O anterior, somado à incapacidade estatal de garantir a segurança das vítimas e de seus líderes no local, dificulta completamente sua incidência em cenários de toma de decisões e estabelece enormes retos que deveria tomar em conta o Estado colombiano para reformular modelos de política e garantir uma participação efetiva.

Palavras-Chave: Participação, defesa, vitima, disenhos institucionais. 


\section{Introducción}

¿Los diseños institucionales que regulan la participación de las víctimas favorecen su incidencia política?, ¿cuáles factores limitan dicha incidencia en espacios de diálogo con el Estado? Este artículo responde estas dos preguntas a través de un análisis comparativo de los diseños institucionales que regulan la participación de las víctimas en Colombia antes y después de la Ley 1448 (2012).

La participación de las víctimas en el diseño, ejecución y seguimiento de la política pública es un tema fundamental, no solo para ellas y sus organizaciones, sino para la sociedad y el Estado por varias razones: 1. Porque a través de la participación, los ciudadanos tienen la expectativa de ser reconocidos como interlocutores válidos, capaces de incidir en la definición de su destino colectivo y en la forma en que el Estado responde a esta compleja y masiva violación de derechos de más de seis millones de colombianos víctimas en el marco del conflicto armado. 2. Porque para el Estado y la sociedad es imperativo conocer y establecer la magnitud, las dinámicas, los impactos y las respuestas a esa masiva violencia teniendo como base la voz de las víctimas. 3. Porque la construcción de una paz estable y duradera implica la garantía de los derechos a la verdad, la justicia, la reparación y las garantías de no repetición, y estos solo pueden llevarse a cabo con su participación real y efectiva.

No obstante su vital importancia, el tema de la participación de las víctimas en espacios creados por el Estado ha sido poco estudiado por la academia colombiana. Si bien la expedición de la Ley de Reparación a Víctimas y Restitución de Tierras, Ley 1448 (2011), es muy reciente, este sistema de participación creado por el Estado tiene sus raíces en el año 2004, momento en el que la Corte Constitucional declaró un estado de cosas inconstitucional (Sentencia T-025, 2014), frente a la respuesta estatal para garantizar los derechos de las personas afectadas por desplazamiento forzado y obligó al gobierno nacional a crear unos escenarios y mecanismos para que ellas pudieran participar en el diseño, ejecución y seguimiento de la política pública para responder a esa tragedia humanitaria.

El gobierno nacional creó entonces unos diseños institucionales para regular la participación de las personas en condición de desplazamiento (de ahora en adelante PD) y estableció unos espacios a nivel municipal, 
departamental y nacional para que sus representantes pudieran dialogar con las autoridades de cada ente territorial $\mathrm{y}$, de esta manera, ser parte activa en la creación y ejecución de la política.

Los y las líderes de diversas organizaciones de población desplazada (de ahora en adelante OPD) participaron en dichos escenarios durante años sin que fueran resueltas sus demandas estructurales y sin que la situación del grueso de esta población cambiara en términos de la garantía de los indicadores de goce efectivo de derechos para superar su condición de desplazamiento. Lo anterior, fue corroborado por la Corte Constitucional al reafirmar que el estado de cosas inconstitucional permanecía a pesar de los esfuerzos gubernamentales (Corte Constitucional, 2009).

Actualmente, con la Ley 1448 (2011) se crea un sistema de participación que parte del anterior contemplado solo para PD y lo amplia a todo el conjunto de víctimas del conflicto armado, independientemente de cuál fue el hecho victimizante que sufrieron. Crea un marco normativo para regular la participación de las víctimas que pretende mejorar las reglas de juego, hacerlas más incluyentes, promover una participación más democrática, y asume 'lecciones aprendidas' del proceso anterior frente a los vacíos sobre la elección de los líderes que los representan y la articulación de los escenarios de participación de los niveles territoriales sub-nacionales con el nivel central.

No obstante lo anterior, dichas mejoras no son suficientes para garantizar que la participación de las víctimas en instancias institucionales se traduzca en una incidencia efectiva, en la que ellas encuentren respuestas concretas a sus demandas estructurales y accedan al goce efectivo de sus derechos, y no lo son porque persisten determinados diseños de política pública que hacen de la participación un ejercicio separado de las instancias de decisión en lo programático y lo presupuestal, y porque, con las nuevas reglas de juego creadas, se abren otras dificultades frente a una participación cualificada y efectiva que obligue al Estado a acoger y poner en marcha las propuestas de las víctimas.

A través de este artículo se pretende analizar los factores relacionados con los diseños institucionales que limitan la incidencia de las víctimas en esos espacios formales de participación. Para ello se planteó una ruta metodológica conformada por tres momentos, 1) se hizo una revisión bibliográfica y documental sobre la participación y una revisión del marco normativo 
y jurisprudencial que establece los diseños que regulan la participación de las víctimas en espacios formales creados por el Estado, 2) se realizaron entrevistas semiestructuradas a líderes de víctimas, representantes de ONG y funcionarios del Estado relacionados con el tema, 3) se sistematizó la información y se elaboró el análisis comparativo de los dos esquemas de participación, antes y después de la Ley de Víctimas, identificando mejoras de la política, nuevas dificultades que obstaculizan el logro de la incidencia que las víctimas desean alcanzar y los factores estructurales de la forma como está concebida la política pública que limitan la participación de las víctimas, más allá del esquema de reglas de juego creadas para regular la participación.

Como resultado se escribe el presente artículo que tiene la siguiente estructura. En primer lugar, se describen tres de los principales aportes conceptuales de la literatura académica relacionados con los diseños que limitan la participación ciudadana en espacios institucionales y que arrojan importantes luces para analizar la participación de las víctimas. En segundo lugar, se hace una comparación de los dos esquemas de participación, el creado para la población en condición de desplazamiento (Ley 387 de 1997 y Decreto 250 de 2005) y el nuevo, que surge a partir de la Ley 1448 (2012) con el fin de identificar las principales mejoras que se establecen, los desafíos que persisten y las nuevas dificultades que se crean con los diseños institucionales recientes. Posteriormente se hace un análisis de aquellos factores estructurales de la política pública de reparación a víctimas que limitan u obstaculizan la incidencia que estas pueden llegar a tener en el logro de sus derechos y, finalmente, se plantean algunas conclusiones.

\section{Factores relacionados con diseños institucionales que limitan la participación}

Los retos que enfrentan los escenarios de participación de las víctimas en el país se encuentran relacionados con las limitaciones generales que encaran los escenarios de participación ciudadana en las democracias contemporáneas, con altos niveles de complejidad institucional y descentralización política y administrativa. Del debate teórico sobre las limitaciones de la participación ciudadana se retomarán aquí tres aspectos que son claves para entender de qué manera los diseños institucionales de la política 
pública de atención y reparación a las víctimas limitan la incidencia que estas pretenden lograr, estos son: a) la extrema dispersión institucional, b) la distancia existente entre los escenarios de participación en lo local y aquellos de decisión en los niveles centrales y c) la violencia contra los líderes y representantes de víctimas y sus organizaciones.

\section{a. La extrema dispersión institucional}

Mascareno (2008) y Bonivento (2009) plantean que se le asignó un alcance muy ambicioso a la participación ciudadana en contextos de descentralización, esta profundizaría la democracia al crear puentes directos para que las poblaciones pudieran incidir en las decisiones sobre sus destinos colectivos, se creía que iba a mejorar la eficiencia y eficacia de las políticas públicas al acercar a gobernantes y gobernados y al posibilitar respuestas más pertinentes de cara a las necesidades locales y también cualificaría la legitimidad del Estado en lo local porque los ciudadanos iban a poder ejercer mayor control ciudadano y premiar o castigar a los políticos vía elecciones. Si bien existen varias experiencias que dan cuenta del poder transformador de la participación ciudadana en contextos específicos como Porto Alegre y Kerala, India, ${ }^{2}$ dichas experiencias no han sido replicables o transferibles a otros contextos, ${ }^{3}$ por el contrario, varios procesos de participación ciudadana locales muestran alcances muchísimo más limitados que no solo obedecen a cómo se concibe e implementa la participación (reglas de juego, espacios, mecanismos), sino que tiene que ver con factores estructurales

1 Para profundizar en estas promesas de la participación ciudadana local y su relación con la mejora de procesos democráticos, ver Programa de las Naciones Unidas para el Desarrollo -PNUD- (2004).

2 Existe una proliferación relevante de la literatura académica que ha investigado a profundidad experiencias exitosas de participación en las que se vislumbra cierta concreción de las promesas de la descentralización. Se encuentran documentados en la literatura casos emblemáticos como el del presupuesto participativo de Porto Alegre en Brasil (De Sousa Santos, 1998) o la planeación descentralizada en Kerala, India ( Isaac y Heller, 2003). Las anteriores experiencias muestran el poder de la participación en la toma de decisiones en espacios determinados y su alcance en la transformación de contextos locales. No obstante, estas experiencias no son transferibles a otros procesos de participación ciudadana en el mundo. Por el contrario, los estudios realizados en esta materia han resaltado también los retos y limitaciones que enfrenta la participación en escenarios descentralizados en su relación con la construcción de sociedades más democráticas. Por la pregunta de investigación que orienta los resultados de este artículo no se aborda la literatura sobre dichas experiencias 'exitosas'.

3 Al respecto, ver Goldfrank y Schneider, 2006. 
que son propios del contexto político e institucional en donde esta tiene lugar y que, aunque escapan de los escenarios deliberativos, tienen gran poder a la hora de limitar el alcance de la participación.

El primero de esos elementos es la extrema dispersión institucional que puede afectar la incidencia de los actores que participan en escenarios formales o institucionales creados por el Estado, como los que se analizan aquí de participación para las víctimas. Con dispersión institucional hago referencia a la profusión de un conjunto diverso y complejo de reglas de juego, normas, leyes y agencias que intervienen en la regulación de determinada política pública, que obedecen a sus propias lógicas y cuya articulación con las restantes no siempre está reglamentada sino que puede ser discrecional. A esta extrema dispersión institucional se suma la inconsistencia en la implementación de la política, que se expresa en contradicciones internas entre las agencias o en determinados vacíos regulatorios y contradicciones en los marcos jurídicos. Estos dos aspectos, dispersión institucional e inconsistencia, generan confusiones respecto a las responsabilidades y competencias de los actores y agencias involucradas en la regulación de la política y acciones descoordinadas por parte de los involucrados. ${ }^{4}$

Lo anterior hace difícil la toma de decisiones de manera articulada, ágil y pertinente porque requiere aunar esfuerzos de agencias que tienen sus propios marcos normativos, responden a sus propias lógicas y no siempre están dispuestas para promover la articulación. Si las decisiones sobre el diseño, la implementación y la ejecución de la política pública dependen de un cúmulo de agencias cada una con sus propios planes y dinámicas y además marcadas por rozamientos o conflictos institucionales, es más difícil para los actores que participan en los espacios institucionales locales lograr respuestas concretas frente a su demandas estructurales (Hernández Bonivento, 2009).

En el caso de la política de atención, asistencia y reparación a las víctimas esta dispersión no es desdeñable. De una parte, el conjunto de agencias

4 Agradezco al profesor Albert Berry, quien me señaló que la extrema dispersión institucional y la inconsistencia en la implementación de la política son dos problemas que están interrelacionados pero son distintos, dado que el primero tiene que ver con complejidad institucional y el segundo va más allá, no está relacionado directamente con la cercanía o cantidad de actores o agencias involucradas, o el tiempo que se dedique a la articulación entre estas, sino que hace referencia a una lógica inconsistente en el modus operandi de las agencias o del cuerpo de legislación de determinada política, simplemente no hay una lógica consistente en el cuerpo de legislación, decretos, etc. o en los modus operandi de las agencias porque sufren o tienen contradicciones internas. 
involucradas en esta política es bastante amplio: el Sistema Nacional de Atención y Reparación Integral a las Víctimas -SNARIV- está constituido por 37 entidades públicas del nivel gubernamental y estatal en los órdenes nacional y territoriales encargadas de formular o ejecutar los planes, programas, proyectos y acciones específicas para la atención y reparación a las víctimas. ${ }^{5}$

La difícil tarea de coordinar el SNARIV ha sido asignada a la Unidad para la Atención y la Reparación Integral a las Víctimas (en adelante, Unidad de Víctimas; Decreto 4800 de 2011). Además de lo anterior la coordinación también se hace entre la nación y los entes territoriales sub-nacionales: departamentos y municipios, que en su mayoría no cuentan con la oferta institucional del SNARIV en sus territorios y por ende la articulación se hace supremamente compleja.

La dispersión también es normativa. El conjunto de leyes y decretos que regulan la reparación para las víctimas es profuso, entre ellos se encuentra todo el marco normativo asociado a la atención a población en condición de desplazamiento (Ley 387 de 1997), el de atención a las víctimas de hechos violentos en el marco del conflicto armado (Ley 418 de 1997), la reparación a víctimas en el marco de Justicia y Paz (Ley 975 de 2005), el de la reparación individual por vía administrativa (Decreto 1290 de 2008) y el de reparación a víctimas y restitución de tierras (Ley 1448 de 2012) y sus decretos reglamentarios. Además, se suma la abundante jurisprudencia emitida por la Corte Constitucional en los últimos años, con sus sentencias y autos de seguimiento, sobre todo relacionados con la atención a la población en condición de desplazamiento.

5 Agencia Nacional para la Superación de la Pobreza Extrema, Archivo General de la Nación, Banco de Comercio Exterior de Colombia, Centro de Memoria Histórica, Consejo Superior de la Judicatura Sala Administrativa, Defensoría del Pueblo, Programa Presidencial e DDHH Y DIH, PAICMA, Departamento Nacional de Planeación, Departamento para la Prosperidad Social, Fiscalía General de la Nación, Finagro, Icetex, Incoder Ministerio de Vivienda, Ciudad y Territorio, Instituto Nacional de Medicina Legal y Ciencias Forenses, Ministerio de Agricultura y Desarrollo Rural, Ministerio de Comercio, Industria y Turismo, Ministerio de Cultura, Ministerio de Defensa Nacional, Ministerio de Educación Nacional, Ministerio de Hacienda y Crédito Público, Ministerio de Justicia y del Derecho, Ministerio de Salud y Protección Social, Ministerio de las Tecnologías de la Información y las Comunicaciones, Ministerio de Relaciones Exteriores, Ministerio del Interior, Ministerio del Trabajo, Policía Nacional, Registraduría Nacional del Estado Civil, Servicio Nacional de Aprendizaje, Superintendencia de Notariado y Registro, Unidad Administrativa Especial de Gestión de Tierras Despojadas, Unidad Administrativa Especial para la Atención y Reparación de Víctimas, Instituto Geográfico Agustín Codazzi. 
Como veremos más adelante, en el apartado 4, Factores estructurales de política que obstaculizan la incidencia de las víctimas, los efectos de esta profunda dispersión institucional y la inconsistencia en la implementación de la política se expresan en la débil articulación entre nación y territorio y en una lábil capacidad institucional, técnica y financiera en lo local para ejecutar la política pública de reparación a víctimas. En los apartados 4.1 y 4.2 se profundiza de qué manera estos dos factores estructurales afectan la incidencia que pueden alcanzar las víctimas en los escenarios locales de participación creados por el Estado.

\section{b. la distancia existente entre los escenarios de participación en lo local $y$ aquellos de decisión en los niveles centrales}

El segundo factor explicativo del contexto institucional que limita la incidencia de los actores que participan está muy relacionado con el anterior. Tiene que ver con la distancia existente entre los escenarios de participación y los de decisión. Al respecto, autores como Gutiérrez (2007) y Vargas (2012), a partir de algunos estudios de caso, muestran cómo las decisiones sobre determinadas políticas y programas sociales le corresponden a una serie de agencias del Estado que no tienen mayor conexión con los espacios de deliberación creados para que los ciudadanos participen.

Por su parte, Massal (2010) y Hevia (2007) plantean que una de las limitaciones más características de escenarios de participación ciudadana en contextos de descentralización se relaciona con la delimitación por parte del poder central de los esquemas de participación creados y de los temas que se debaten en lo local, así como con la poca incidencia política de los actores que participan porque los escenarios deliberativos locales están lejos de las instancias de decisión en el nivel central. En esta misma vía se encuentran autores que señalan las limitaciones generadas por las destinaciones presupuestales, en la medida en que el grueso de los recursos no necesariamente responde, atiende y se articula a las decisiones y ejercicios de planeación realizados en esas instancias de participación descentralizadas, tal como lo sugieren los trabajos de Finot (2002), Lippez (2010) y Vargas (2012). Aquí hay puntos de vista encontrados entre quienes señalan a ultranza que se requiere mayor autonomía de los entes locales de gobierno, que les permita ejecutar dineros para libre destinación en porcentajes más altos, y Lippez 
y otros que plantean de forma enfática los riesgos con relación a la mayor facilidad de cooptación de los presupuestos locales por parte de intereses privados en medio del contexto del conflicto armado.

Este aspecto es característico de la política pública de atención y reparación a víctimas en la que existe una prevalencia de lo sectorial sobre lo territorial en lo que respecta a las decisiones sobre los lineamientos de la política pública y la destinación presupuestal. Esto limita los procesos de planeación en los escenarios locales de participación que no cuentan con los recursos necesarios para ser ejecutados y dificulta que las propuestas de las víctimas en lo local asciendan a lo nacional y que sean tenidas en cuenta. Si bien, como veremos aquí, se han dado algunos avances para crear un sistema de corresponsabilidad que permita articular la nación y el territorio y apoyar con recursos y asistencia técnica a los entes territoriales en sus ejercicios de planeación, este proceso no avanza tan rápido como la ley lo requiere y aún no está clara la reglamentación que permita establecer responsabilidades, pisos y techos presupuestales para la adecuada articulación. En últimas, si estos mecanismos y procesos pensados para la articulación no arrancan, enfrentamos el riesgo de que se repita el fracaso del esquema anterior de participación en el que los escenarios de decisión sobre las líneas programáticas y presupuestales de política pública no tenían conexión con los escenarios de planeación locales.

Como veremos en el apartado 4, Factores estructurales de política que obstaculizan la incidencia de las víctimas, las decisiones gruesas en términos programáticos y presupuestales sobre el desarrollo de la política competen a múltiples agencias y actores del orden sectorial nacional y escapan a los entes territoriales, la gran mayoría de ellos caracterizados por una débil capacidad técnica y financiera en lo local para ejecutar la política de atención a víctimas, lo anterior, como se profundizará más adelante, afecta la incidencia de las victimas porque aleja los escenarios de decisión de aquellos escenarios locales de participación.

\section{c. La violencia contra los líderes y representantes de víctimas $y$ sus organizaciones}

En el contexto colombiano, este tercer factor es uno de los más graves y limita de manera importante la participación de las víctimas en los espacios 
institucionales de participación. La violencia letal y no letal es ejercida por actores armados diversos, en los contextos locales, contra los líderes y lideresas de organizaciones de víctimas, contra reclamantes de tierras, defensores de derechos humanos, campesinos, indígenas y población afrodescendiente. Dicha violencia busca "castigar" e "intimidar" a las poblaciones frente a los procesos de reparación y restitución de tierras, aniquilar y desestructurar los procesos organizativos y frenar la política de reparación.

Se retoman estos tres factores estructurales en el apartado 4 para explicar algunas características del contexto institucional de la política pública de reparación a víctimas que limitan la incidencia de estas en escenarios locales de participación: es un contexto institucional marcado por la dispersión de las agencias del Estado encargadas de reparar a las víctimas, en un gobierno multinivel -local, departamental y nacional- desarticulado, que propendió por la creación de un sistema de implementación de la política, descentralizado pero que no cuenta con la capacidad económica, técnica y fiscal para el desarrollo de las reivindicaciones de las víctimas, y, además de lo anterior, caracterizado por la imposibilidad del Estado para garantizar medidas de seguridad y protección a los líderes que participan en los escenarios de participación.

\section{Comparación de los esquemas de participación: antes y después de la Ley 1448 de 2012}

\subsection{Esquema de participación creado para la población en condición de desplazamiento}

En el año 2004, la Corte Constitucional le exigió al gobierno nacional tomar una serie de medidas para superar el estado de cosas inconstitucional con relación a la masiva violación de los derechos de las personas víctimas del desplazamiento forzado, situación que responde a políticas estatales inadecuadas y que demuestra una clara responsabilidad del Estado en la permanencia de esa situación. ${ }^{6}$ Entre estas medidas le exigió promover y

6 "La Corte declara un estado de cosas inconstitucional cuando se encuentra con situaciones de violación masiva de derechos que responden a políticas estatales inadecuadas y que demuestran 
garantizar la participación de la PD en la formulación, implementación y seguimiento de la política pública. Para cumplir con dicha exigencia el gobierno estableció tres medidas:

La primera medida reactivó los Comités Territoriales de atención para la población desplazada creados por la Ley 387 de 1997, los cuales hacen referencia a comités de planeación municipales y departamentales en los que los funcionarios del Estado en lo local, las organizaciones sociales y los representantes de la PD establecen programas y proyectos para atender a la PD.

En segundo lugar, el gobierno creó cuatro mesas nacionales en el marco del Consejo Nacional para la Atención Integral para la PD: ${ }^{7}$ 1) de protección y prevención, 2) de atención humanitaria de emergencia, 3) de restablecimiento socio-económico, y estableció que, además de la participación de los directores o funcionarios de las diversas entidades del Estado relacionadas directamente con cada una de las fases de atención, debían participar con carácter obligatorio dos representantes de población desplazada en cada una de esas mesas. 4) La cuarta mesa, de fortalecimiento del proceso organizativo de la población desplazada, estaría conformada únicamente por representantes o líderes de las OPD. Estas mesas temáticas también se conformarían en los municipios y departamentos en el marco de los comités territoriales de atención integral para la PD.

Para la tercera el gobierno propuso como herramienta de planeación de dichos comités lo que se define como el Plan Integral Único (PIU), el cual establece los programas y proyectos para atender a la PD y debe construirse de manera participativa a partir de los insumos generados por las mesas temáticas. Para que sea viable, el PIU debe tener soporte en el presupuesto de cada ente territorial. ${ }^{8}$

la existencia de una clara responsabilidad del Estado; y cuando además, las soluciones individuales alcanzadas por vía de tutela no hacen sino convertir a esta acción judicial en un requisito adicional para obtener la protección de los derechos, y establecer una discriminación entre los que la presentan y los que no lo hacen" (Uprimny, 2004, p. 84).

7 Para posibilitar el funcionamiento del sistema Nacional de Atención Integral para la Población Desplazada -SNAIPD-, que aglutina a las entidades del Estado involucradas en la atención a esta población, la Ley 387 de 1997 creó el CNAIPD, Consejo Nacional de Atención Integral a la Población Desplazada por la Violencia, como órgano consultivo y asesor, encargado de formular la política y garantizar la asignación presupuestal de los programas que las entidades responsables del funcionamiento del SNAIPD tienen a su cargo.

8 Colombia. Presidencia de la República de Colombia, Decreto 250 de 2005. 
De esta manera, el gobierno nacional en el año 2005, con ayuda de Unidad Técnica Conjunta UTeC y la desaparecida Acción Social, convocó a seis organizaciones de población desplazada que se reconocían a sí mismas como nacionales y creó la cuarta mesa con la participación de representantes de dichas organizaciones. Pero este proceso tuvo varias limitantes: En primer lugar, fue un proceso de arriba para abajo que no tuvo en cuenta lo que estaba ocurriendo en los municipios, no contempló ningún mecanismo de articulación que posibilitará el ascenso de las demandas en los entes territoriales a los escenarios nacionales de interlocución, ni garantizó algún amarre entre la representación a nivel territorial y la nacional. ${ }^{9}$ En este sentido, las organizaciones de población desplazada en lo local no siempre hacían parte de organizaciones del nivel nacional, ni las mesas en lo municipal se articulaban con el nivel superior.

En segundo lugar no estableció reglas claras de juego frente a los mecanismos de representación, los periodos de tiempo, la rotación o la posibilidad de entrada de nuevos actores y la representación regional. Los dos aspectos anteriores lesionaron la legitimidad de esos escenarios, pues algunas personas señalaron que no se sentían representadas por esos líderes (Vargas, 2012).

En tercer lugar, se generaron tensiones al momento de identificar quiénes eran los interlocutores de grupos poblacionales que no necesariamente estaban bajo la forma de organizaciones de población desplazada, sino que tenían sus propias formas de organización tradicional, de manera específica con grupos indígenas y grupos afro-descendientes.

La cuarta limitante reside en que no existía claridad frente a las responsabilidades y competencias de los actores estatales que debían garantizar

9 "No existen mecanismos explícitos y claros que promuevan el ascenso de las demandas de las OPDs locales a las nacionales de manera sistemática ni a los espacios de decisión centrales en los que se dialoga con las entidades sectoriales del Estado en lo nacional. No todas las OPDs de un municipio están articuladas a organizaciones nacionales ni tienen representación en los espacios institucionales de diálogo con el Estado en los niveles municipal, departamental y nacional porque no existen mecanismos que exijan y promuevan dicha articulación, no todas las organizaciones conocen estos espacios y, en otros casos, no les interesa hacer parte de colectivos más amplios sino trabajar en su espacio local, ya sea por distancias políticas con esas organizaciones o porque tienen como objetivos metas más inmediatas. La articulación es discrecional, depende de los esfuerzos de algunas organizaciones nacionales que intentan articular en su espacio a las organizaciones locales, pero estos esfuerzos no implican necesariamente que circule la información de abajo-arriba y viceversa, ni que existan agendas de trabajo conjuntas a través de las cuáles se logren las reivindicaciones que exigen a los gobiernos municipal, departamental y nacional" (Vargas, 2012, p 52). 
las condiciones para la participación de la PD en lo local. Si bien la entidad responsable fue Acción Social, sus esfuerzos se centraron en acompañar técnica y financieramente a la cuarta mesa en el nivel nacional y en el desarrollo de programas de capacitación y fortalecimiento técnico de algunas organizaciones en pocas regiones del país.

Entonces se crearon esos escenarios de participación en los que los representantes de las organizaciones de población desplazada pudieron dialogar con las autoridades estatales, pero ellos no lograron incidir en decisiones programáticas y presupuestales que se concretarán en una verdadera atención y reparación para la PD. Durante esos años no lograron respuestas concretas y pertinentes frente a las demandas estructurales más sentidas de la población a la que representaban: restitución de vivienda, tierras y patrimonio, restablecimiento socioeconómico, entre otros; la política tuvo un carácter asistencial muy marcado que dio mayor peso a la ayuda humanitaria de emergencia.

Las condiciones estructurales de pobreza, exclusión y violación de los derechos de esta población se agudizaron. Lo anterior fue ratificado por la Comisión de Seguimiento de política pública que señaló que el 97\% de la población en condición de desplazamiento se encontraba por debajo de la línea de pobreza y el 80\% por debajo de la línea de indigencia (Comisión de Seguimiento..., 2008). Por ello, la Corte Constitucional en el año 2009 ratificó el estado de cosas inconstitucional en el que afirmó que a pesar del aumento presupuestal del gobierno para atender a la PD y de las medidas y esfuerzos de los últimos cinco años, la situación de esta población, en términos de goce efectivo de sus derechos, era desastrosa.

Entre muchas de las causas explicativas de la poca capacidad del Estado para acoger y dar respuesta a las reivindicaciones de la PD en estos espacios, estuvieron dos de orden estructural que señalamos aquí porque están relacionadas con los diseños institucionales de la política pública y con la forma como se ha concebido la descentralización en el país. De una parte, el grueso de la asignación presupuestal se hizo a nivel sectorial y no territorial y la mayoría de municipios categoría 2 a 6 manifestaron que no tenían los recursos necesarios para garantizar el goce efectivo de sus derechos (Pedraza y Restrepo, 2009). De otra parte, los lineamientos y decisiones programáticas de política pública se decidieron en el nivel central y no existieron mecanismos formales de articulación que contaran con la 
participación de las autoridades locales en el diseño de esos lineamientos o que acogiera de manera permanente y sistemática sus demandas, esa articulación dependió de la discrecionalidad de cada sector y del tipo de presencia que tuviese determinada agencia del Estado sectorial en lo regional y en lo local (Pedraza y Restrepo, 2009).

Teniendo en cuenta lo anterior, Vargas señala que ese esquema de participación convirtió los escenarios de diálogo y planeación en espacios desgastantes para las personas en condición de desplazamiento, en los que su incidencia política se vio en extremo limitada porque las decisiones con respecto a sus necesidades estructurales se tomaban en otros espacios y no en aquellos que se suponía eran los escenarios privilegiados para la planeación en lo local.

En diciembre del año 2011 fue aprobada la Ley de Víctimas y Restitución de Tierras en el Congreso, por la cual se dictan medidas de atención, asistencia y reparación integral a las víctimas del conflicto armado interno dentro de un marco de justicia transicional. La aprobación de dicha ley, a pesar de las limitaciones que tiene, ha sido un paso fundamental porque pone en la agenda pública el tema de las víctimas ${ }^{10}$ exige su reconocimiento, crea una nueva institucionalidad para llevar a cabo la reparación, ${ }^{11}$ y abre una ventana de oportunidad política para que las personas que abandonaron su tierra o fueron despojadas puedan exigir su restitución.

Este marco regulatorio retomó muchos aspectos del sistema creado en años anteriores para atender a la PD, en este sentido, trasladó las funciones del Sistema Nacional de Atención Integral a la Población Desplazada por la Violencia-SNAIPD-, al ahora llamado Sistema Nacional de Atención y Reparación Integral a las Víctimas -SNARIV-, ${ }^{12}$ y las funciones del antiguo Consejo Nacional de Atención Integral a la Población Desplazada-CNAIPD- hacia el nuevo Comité Ejecutivo para la Atención y Reparación Integral a las Víctimas (Decreto impensable.

10 Durante el gobierno del presidente Álvaro Uribe Vélez una ley de este tipo hubiese sido

11 Con la Ley 1448 de 2011 se creó una nueva institucionalidad encargada de liderar las acciones del Estado para atender y reparar integralmente a las personas que han sido víctimas del conflicto: La Unidad de Atención y Reparación Integral para las Víctimas (en adelante, Unidad de Víctimas) y la Unidad Administrativa Especial de Gestión de Restitución de Tierras Despojadas (en adelante, Unidad de Tierras).

12 Es el sistema conformado por 37 entidades públicas del nivel gubernamental y estatal en el orden nacional y territorial, encargado de formular o ejecutar los planes, programas, proyectos y acciones específicas tendientes a la atención y reparación integral de las víctimas. 
0790 de 2012). Dicho comité es la máxima instancia de decisión del SNARIV, establece las políticas, estrategias e instrumentos de planificación, gestión, seguimiento y evaluación, con el fin de materializar las medidas para garantizar la atención, asistencia y reparación integral a las víctimas. ${ }^{13}$

Con la aprobación de esta nueva ley, el esquema de participación, antes pensado para la PD, se amplió a las personas afectadas por los diversos hechos victimizantes, y aunque conserva fundamentalmente los mismos escenarios de participación en lo municipal y departamental, se crearon unas nuevas reglas de juego para llenar vacíos regulatorios anteriores, relacionados con las elecciones de los líderes, la conformación de las mesas, los tiempos, requisitos, prohibiciones e incentivos para la participación, así como la articulación de los espacios municipales con los de los niveles superiores.

\subsection{El esquema de participación creado para las víctimas del conflicto armado en el marco de la Ley 1448}

La Ley 1448 de 2011 especifica que es deber del Estado promover y garantizar las condiciones y los espacios para la participación efectiva de las víctimas en los niveles nacional, departamental y municipal con un enfoque diferencial (art. 193) garantizar los medios e instrumentos para la elección de sus representantes en las instancias de decisión (art. 192), crear unas reglas de juego contenidas en un protocolo de participación para regular la participación (Resolución 0388 de 2013; Ley 1448 de 2011, art. 194) y encarga a la Unidad Administrativa Especial de Atención y Reparación Integral a las Víctimas como la entidad responsable de implementar los mecanismos y estrategias para que dicha participación sea efectiva y tenga un enfoque diferencial. ${ }^{14}$

13 El Comité Ejecutivo está integrado por el Presidente de la República, los Ministros del Interior, de Justicia, Hacienda y Agricultura; los directores del Departamento Nacional de Planeación, la Agencia Presidencial para la Acción Social y la Cooperación Internacional y la Unidad Administrativa Especial para la Atención y Reparación Integral a las Víctimas, que ejercerá la secretaría técnica del Comité. La Unidad de Víctimas además ejerce la coordinación del SNARIV" (Ley 1448 de 2011, art. 164).

14 Departamento Administrativo de la Función Pública. Decreto número 4802 de 2011. Ver también Ministerio de Justicia y del Derecho. Decreto número 4800 de 2011, que reglamenta y estipula genéricamente la participación efectiva, los espacios de participación de las víctimas, las Mesas de Participación, las organizaciones de víctimas, las organizaciones defensoras de los derechos de las víctimas, los voceros y representantes, así como también los procedimientos de elección y funcionamiento de los espacios de participación y representación de las víctimas. 
En el nuevo esquema se mantienen las mesas de participación en todos los niveles pero se cambia su conformación y se mantienen también los comités territoriales, pero ahora son llamados Comités Territoriales de Justicia Transicional. Asimismo, se establece la representación de las víctimas en varias instancias de decisión:

Tabla 1. Espacios de participación de las víctimas

\begin{tabular}{|l|l|}
\hline \multicolumn{1}{|c|}{ (Decreto 4800 de 2011, art. 263) } & \multicolumn{1}{c|}{ Número de personas víctimas que participan } \\
\hline $\begin{array}{l}\text { Mesas municipales, distritales, departamentales y na- } \\
\text { cional de víctimas }\end{array}$ & $\begin{array}{l}\text { Las mesas municipales no pueden superar los } \\
24 \text { miembros. } \\
\text { Las mesas departamentales no pueden superar } \\
\text { los } 26 \text { miembros. }\end{array}$ \\
\hline Comités territoriales de Justicia Transicional & $\begin{array}{l}\text { Participan dos representantes de las Mesas de } \\
\text { Víctimas de acuerdo al nivel territorial }\end{array}$ \\
\hline $\begin{array}{l}\text { Comité Ejecutivo para la Atención y Reparación a las } \\
\text { Víctimas }\end{array}$ & $\begin{array}{l}\text { Participan dos representantes de la Mesa de } \\
\text { Víctimas del nivel nacional. }\end{array}$ \\
\hline $\begin{array}{l}\text { Consejo Directivo de la Unidad Administrativa Especial } \\
\text { de Gestión de Restitución de Tierras Despojadas }\end{array}$ & $\begin{array}{l}\text { Participan dos representantes de la Mesa } \\
\text { Nacional de Víctimas. }\end{array}$ \\
\hline Comisión de Seguimiento y Monitoreo & $\begin{array}{l}\text { Participan tres representantes de la Mesa } \\
\text { Nacional de Víctimas. }\end{array}$ \\
\hline Consejo Directivo del Centro de Memoria Histórica & $\begin{array}{l}\text { Participan dos representantes de la Mesa } \\
\text { Nacional de Víctimas. }\end{array}$ \\
\hline
\end{tabular}

Como ya existía un esquema de participación, se definió un proceso de transición de las funciones que tenía la Mesa Nacional de Fortalecimiento a Organizaciones de Población Desplazada que con el nuevo esquema debían ser asumidas por la Mesa de Participación de Víctimas. En este sentido, el Decreto 0790 de 2012 indicó que la Unidad sería la encargada de orientar dicha transición. Para ello, a finales de junio del año 2012, la Unidad convocó entonces a unos 'espacios de interlocución transitorios' en los entes territoriales que incluía a representantes de las antiguas mesas de PD, pero además establecía la nueva participación de personas afectadas por diversos hechos victimizantes. Dicho mecanismo tuvo tres funciones específicas: i) la discusión del protocolo de participación efectiva a través del cual se consultaría y definirían las reglas de juego, ii) la elección de representantes a las instancias de interlocución a nivel municipal, departamental y nacional 
y iii) la participación en la elaboración de los Planes de Acción Territorial (antes llamados Planes Integrales Únicos PIU). ${ }^{15}$

Si bien este mecanismo fue objeto de algunas críticas por la forma como se dio la participación de las víctimas, tuvo entre sus resultados la discusión y, de forma extemporánea, la aprobación del protocolo de participación efectiva (Resolución 0388 de 10 de mayo de 2013), a través del cual se fijan reglas, criterios, prohibiciones y requisitos para la elección, de todos aquellos que van a ser postulantes para las elecciones de las mesas.

"La virtud de este protocolo es que no es un manual de buenas intenciones sino que es un documento que tiene naturaleza jurídica. Es el primer protocolo de participación efectiva de víctimas que se hace en el país, sabemos que con la PD hubo un protocolo pero era un documento de recomendaciones, no fijaba responsabilidades institucionales, no imponía requisitos a quienes desearan participar y de acuerdo a miembros de la Comisión Interamericana de Derechos Humanos este es el único protocolo de participación para víctimas elaborado en todos los países que han llevado a cabo un proceso de reparación a víctimas en el marco de la justicia transicional. Este es un documento made in Colombia, estamos innovando en el tema y es bien importante" (Vargas, 23 de junio de 2013, entrevista a Bárbara González de la Corporación Viva la Ciudadanía).

El protocolo establece que las mesas sirven como espacios de diálogo y concertación con las autoridades en los entes territoriales, como plataforma para la presentación de propuestas, allí eligen a sus representantes para otros espacios de participación en los niveles superiores, discuten y concertan el Plan de Acción Territorial -PAT-, participan en ejercicios de rendición de cuentas, veeduría y seguimiento a los programas de atención y reparación, entre otras.

15 "En el proceso llevado a cabo con los Espacios de Interlocución Transitorios, se inscribieron 2.120 Organizaciones de Víctimas en municipios y departamentos del país, y 323 Organizaciones Defensoras de los Derechos de las Víctimas. Por su parte, el Espacio de Interlocución Transitorio $\mathrm{Na}$ cional de Participación quedó conformado por 103 representantes de las víctimas, de los cuales 46 representantes son mujeres, de los diferentes departamentos, representando enfoques diferenciales y enfoques étnicos, que equivale al $40 \%$ del total de las personas que componen este Espacio Nacional. De las 46 mujeres, 32 son líderes víctimas del desplazamiento forzado, equivalente a un 28,3\% del total de miembros del Espacio de Interlocución Transitorio Nacional" (SNARIV, 2013, p. 29). A mayo de 2013 se contaba con 3.311 organizaciones de víctimas y organizaciones defensoras de los derechos de las víctimas, registradas e inscritas en los espacios de participación previstos por la ley. 
Tabla 2. Esquema de conformación de las mesas

\begin{tabular}{|c|c|c|c|}
\hline Mesa & $\begin{array}{c}\text { Elección de las organizaciones de } \\
\text { víctimas } \mathrm{OV}\end{array}$ & $\begin{array}{c}\text { Participación de organizaciones } \\
\text { defensoras } O D V\end{array}$ & Secretaría técnica \\
\hline $\begin{array}{l}\overline{\widetilde{J}} \\
\stackrel{2}{0} \\
\stackrel{0}{\Xi} \\
\stackrel{3}{z}\end{array}$ & $\begin{array}{l}\text { Se eligen por las Organizaciones de } \\
\text { Víctimas (OV), previamente inscritas } \\
\text { ante la personería municipal y distrital. } \\
\text { Por votación de la totalidad de los ins- } \\
\text { critos según los cupos a proveer por } \\
\text { hecho victimizante y por sectores victi- } \\
\text { mizados (enfoque diferencial). }{ }^{16}\end{array}$ & $\begin{array}{l}\text { Las ODV tendrán dos representan- } \\
\text { tes para cumplir una función de } \\
\text { acompañamiento técnico y políti- } \\
\text { co, con voz, pero sin voto, elegidas } \\
\text { por votación de la totalidad de los } \\
\text { inscritos. }\end{array}$ & $\begin{array}{l}\text { El Personero Mu- } \\
\text { nicipal y Distrital } \\
\text { convoca y ejer- } \\
\text { cerá la Secretaría } \\
\text { Técnica. }\end{array}$ \\
\hline 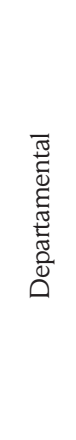 & $\begin{array}{l}\text { Se eligen de las ov inscritas en el res- } \\
\text { pectivo ámbito departamental y de } \\
\text { los dos delegados de cada uno de los } \\
\text { municipios y distritos donde se hubiere } \\
\text { elegido Mesa de Participación Local. } \\
\text { Se elige a cada uno de los representan- } \\
\text { tes, por votación de la totalidad de los } \\
\text { delegados de cada municipio y de las } \\
\text { organizaciones inscritas en el nivel de- } \\
\text { partamental, según los cupos a proveer } \\
\text { por hecho victimizante y por sectores } \\
\text { victimizados (enfoque diferencial). }\end{array}$ & $\begin{array}{l}\text { En las Mesas Departamentales, } \\
\text { las Organizaciones Defensoras de } \\
\text { Víctimas (ODV), previa inscripción } \\
\text { ante las defensorías regionales, ten- } \\
\text { drán } 4 \text { representantes para cumplir } \\
\text { una función de acompañamiento } \\
\text { técnico y político, con voz, pero } \\
\text { sin voto. } \\
\text { Dichos representantes serán ele- } \\
\text { gidos por votación de la totalidad } \\
\text { de los delegados de las ov de cada } \\
\text { municipio y de las ov inscritas en } \\
\text { el nivel departamental. }\end{array}$ & $\begin{array}{l}\text { El Defensor Re- } \\
\text { gional convoca y } \\
\text { ejerce la Secreta- } \\
\text { ría Técnica }\end{array}$ \\
\hline $\begin{array}{l}\overline{\mathbb{Z}} \\
\stackrel{0}{\tilde{U}} \\
\mathbb{Z}\end{array}$ & $\begin{array}{l}\text { Se eligen por medio de los delegados } \\
\text { de cada uno de los departamentos don- } \\
\text { de se hubiere elegido Mesa de Parti- } \\
\text { cipación. } \\
\text { En la elección de la Mesa Nacional se } \\
\text { elegirá cada uno de los representantes, } \\
\text { según los cupos a proveer por hecho } \\
\text { victimizante, y por sectores victimiza- } \\
\text { dos (enfoque diferencial), dentro de los } \\
\text { respectivos delegados departamentales. }\end{array}$ & $\begin{array}{l}\text { En la Mesa Nacional, las Organi- } \\
\text { zaciones Defensoras de Víctimas } \\
\text { (oDV), previa inscripción ante la } \\
\text { Defensoría del Pueblo, tendrán } \\
\text { ocho representantes para cumplir } \\
\text { una función de acompañamiento, } \\
\text { con voz, pero sin voto. }\end{array}$ & $\begin{array}{l}\text { El Defensor del } \\
\text { Pueblo es el en- } \\
\text { cargado de convo- } \\
\text { car y ejercer la Se- } \\
\text { cretaría Técnica. }\end{array}$ \\
\hline
\end{tabular}

16 Según el Artículo 26 del protocolo de participación, los cupos para la composición de las mesas municipales son los siguientes:

1. Dos (2) cupos para representantes de ov postulados por hechos victimizantes contra la vida y la libertad (homicidios, masacres, secuestro, desaparición forzada), de los cuales por lo menos uno tendrá que ser mujer.

2. Dos (2) cupos para representantes de ov de hechos victimizantes contra la integridad física, de los cuales por lo menos uno tendrá que ser mujer.

3. Dos (2) cupos para representantes de ov de violencia sexual, de los cuales por lo menos uno tendrá que ser mujer.

4. Ocho (8) cupos para representantes de ov de desplazamiento forzado, de los cuales por lo menos cuatro tendrán que ser mujeres.

5. Un (1) cupo para un representante de las víctimas LGBTI.

6. Un (1) cupo para una representante de organizaciones de mujeres víctimas.

7. Un (1) cupo para un representante de víctimas jóvenes (entre 18 y 28 años).

8. Un (1) cupo para representantes de víctimas de adultos mayores (más de 60 años).

9. Un (1) cupo para un representante de víctimas en condición de discapacidad. 
Cuando el protocolo se refiere a cupos a proveer por los hechos victimizantes establece los siguientes: contra la vida y la libertad (que aglomera homicidios, masacres, secuestro, desaparición forzada), contra la integridad física o psicológica (que incluye tortura, minas), violencia sexual y desplazamiento forzado. Y cuando indica sector victimizado hace referencia al enfoque diferencial de las víctimas: LGBTI, mujeres, jóvenes (entre 18 y 28 años), adultos mayores (más de 60 años), en condición de discapacidad, de comunidades indígenas, afrocolombianas, negras, raizales palanqueras y rom.

\subsection{Diseños que introducen mejoras con relación al esquema de participación anterior}

Con relación al esquema anterior de participación, las nuevas reglas de juego establecen al menos cinco aspectos que buscan llenar vacíos existentes con el fin de facilitar la incidencia de las víctimas y de mejorar el mecanismo de participación: 1. promueve la inclusión de personas afectadas por diversos hechos victimizantes, 2. plantea reglas de juego para la elección de representantes, 3. crea unos mecanismos de articulación entre los niveles territoriales, 4 . establece sesiones de diálogo abiertas con cuerpos colegiados y 5 . ofrece algunos incentivos para la participación:

\subsubsection{Pretende promover una mayor inclusión}

Se abren y amplían los espacios de participación para representantes de las víctimas de diversos hechos victimizantes. Esto abre nuevos retos para los funcionarios del Estado y para las víctimas de desplazamiento forzado acostumbradas en estos escenarios de participación a hablar fundamentalmente

10. Un (1) cupo para un representante de comunidades indígenas, designado por su respetiva autoridad tradicional.

11. Un (1) cupo para un representante de comunidades tradicionales afrocolombianas, designado por su respectiva autoridad.

12. Un (1) cupo para un representante de comunidades rom.

13. Dos (2) cupos para dos miembros elegidos entre las ODV inscritas.

Para las mesas departamentales y nacionales las categorías son similares. Lo que cambia es el número de cupos. Para analizar esto al detalle ver Unidad de Víctimas, Resolución 0388 de mayo de 10 de 2013, Protocolo de Participación. 
de las reivindicaciones de la PD, implica la circulación de nuevos lenguajes, de nuevos discursos, complejiza el proceso de atención y reparación y exige el fortalecimiento de capacidades de los actores involucrados en el reconocimiento de los demás.

\subsubsection{Plantea reglas de juego para la elección de representantes}

Una de las dificultades del esquema anterior de participación y que constituyó una verdadera fuente de conflicto entre diversas OPD fue la lucha política por el acceso a los espacios de diálogo con el Estado. En este sentido Vargas (2012) señala que

[...] estas tensiones entre las OPD son propias de todo proceso de elección en el que los actores buscan ser elegidos y poner a la gente de su colectivo en los lugares de representación. No obstante, estas tensiones devienen en conflictos entre las OPD cuando no existen reglas claras de juego frente a los mecanismos de representación, a los periodos de tiempo, la rotación o la posibilidad de entrada de nuevos actores y la representación regional. Es decir, cuando los diseños construidos para la representación no generan condiciones de igualdad para todos en su derecho a ser elegidos, sino que son diseños que generan exclusiones (Vargas, 2012b, 169).

Con el nuevo esquema de participación se establecen varias de esas reglas de juego que no estaban contempladas en el esquema anterior, entre ellas: se indica el procedimiento para poder ser elegido (inscripción previa de las Organizaciones de Víctimas ov y Organizaciones Defensoras de Víctimas ODV ante la Personería o la Defensoría, según el caso, postulación de los candidatos según los cupos a proveer por hecho victimizante y por sectores victimizados), el mecanismo para las elecciones (por consenso y si este no se da por voto de mayoría simple), los tiempos de duración de una representación (un año, máximo dos, pues solo se permite una reelección) y la rotación de personas en los cargos. También se establecen requisitos para ser representantes de las víctimas en las mesas de participación (como estar inscrito en el Registro Único de Víctimas, no tener antecedentes penales ni disciplinarios) y prohibiciones para los miembros de las mesas (como celebrar contratos con las entidades del SNARIV, gestionar a nombre propio o de un tercero dádivas o recursos). 
Lo anterior genera seguridades para que las organizaciones de víctimas que deseen postular a sus delegados sepan cómo pueden presentarse y ser elegidas bajo unas condiciones y criterios claros y se preparen mejor para la contienda política, también "busca promover la llegada de nuevos liderazgos y mayor transparencia al momento de las elecciones" (Vargas, 23 de junio de 2013, entrevista a Bárbara González de la Corporación Viva la Ciudadanía).

No obstante el esfuerzo del protocolo, hay varios vacíos en la regulación que generan ambigüedad y exclusiones en las reglas de juego:

1. Tal y como está planteada la elección de los representantes en el protocolo (por cupos a proveer de hechos victimizantes y sectores victimizados) esta no es la más adecuada porque no se ajusta a la realidad y a las dinámicas organizativas de las víctimas en muchos de los municipios del país:

En el trabajo de campo hemos encontrado unas paradojas muy fuertes que no sabemos cómo se van a resolver, por ejemplo, en el protocolo dice "miembros por organizaciones que se postulen por hechos victimizantes" pero tenemos una realidad y es que la mayoría de procesos organizativos aglomeran un universo de víctimas de todos los hechos victimizantes. No necesariamente hay en todos los municipios de Colombia una organización de desaparecidos, otra de secuestrados, otra de mujeres que han sido violadas, eso no existe. Convergen en muchos casos en una gran organización. Tenemos municipios en los que existe una sola organización y la pregunta es ientonces esa organización se postula a todos los hechos victimizantes y todos estos miembros de esta misma organización hacemos la mesa? O también nos pasa que no tenemos organizaciones sino seis o siete víctimas que decidieron, digamos, pegarse un poco al proceso de participación, hacer un acto y decir "nosotros seis nos juntamos para avanzar en el tema" y entonces estos seis iqué plenario o asamblea de víctimas tienen? Si son solo seis. Pero igual son seis víctimas que tienen su derecho a participar y se les debe garantizar. ¿Cómo hacemos si yo tengo una organización muy grande y muy sólida, yo puedo postular a todos los hechos victimizantes, porque mi organización congrega víctimas de todo? O ¿cuántos cupos como organización tengo derecho a postular? ¿puedo postular los dos de secuestro, los dos de homicidio, los de desplazamiento? Pero finalmente terminamos siendo la misma organización en la mesa, 
siendo que hay otras organizaciones que pueden estar ahí, entonces ieso cómo se regula? (Vargas, 20 de junio de 2013, entrevista a María Angélica Gómez, especialista de la Consultoría para los Derechos Humanos y el Desplazamiento Forzado -CODHES-).

De acuerdo a lo anterior, la dinámica organizativa puede ser muy diversa en cada municipio y al parecer escapa de las reglas de juego propuestas en el protocolo, en algunos es inexistente la organización de víctimas, en otros, una sola organización congrega a personas afectadas por diversos hechos, hay un vacío con relación a cuántas personas puede postular una sola organización y no está claro qué ocurre en aquellos territorios en los que no hay sino una sola, o en las que no se atiende a todos los hechos victimizantes, etc.

2. El otro aspecto que ha generado confusiones en los territorios tiene que ver con la participación de los pueblos y grupos indígenas y afrodescendientes. El protocolo señala que aún no se han concertado con estos grupos étnicos las reglas de juego para su participación, así que la Unidad tendrá un plazo de diez meses para dialogar y establecer unos protocolos étnicos que respondan a sus necesidades. Mientras tanto, otorga en las mesas municipales un cupo para un delegado indígena y uno afro, designados por su respectiva autoridad tradicional. Esto ha generado un vacío regulatorio en territorios ampliamente poblados por grupos étnicos, confusiones frente a su implementación y exclusiones en la participación, María Angélica Gómez, de Codhes, lo plantea claramente:

Frente a los indígenas hay territorios donde tenemos más de dos, más de cinco, más de diez pueblos indígenas distintos y solo hay un cupo provisto en el protocolo ¿yo, cómo hago para que este señor hable por mí si es que usted y yo somos totalmente distintos?. Ni siquiera hablamos la misma lengua, ¿usted cómo va a priorizar lo que yo quiero que se priorice si solo es un cupo, el suyo. Entonces allí hay otro escenario difícil (Vargas, 20 de junio de 2013, entrevista a María Angélica Gómez, especialista de la Consultoría para los Derechos Humanos y el Desplazamiento Forzado -Codhes-).

Los territorios con fuerte presencia étnica tienen particularidades que no encuentran respuesta en el protocolo actual que regula la participación. 
Y muchas de la ambigüedades y vacíos tienen que ver con la forma de entender el enfoque diferencial y el desconocimiento de las dinámicas organizativas diversas que pueden existir dentro de un mismo grupo étnico.

Frente a los afros, en Cartagena nos pasó que el 40 \% de la población desplazada es afro pero no vienen necesariamente de consejos comunitarios, entonces la pregunta es iel protocolo étnico que va a salir para quién es? Es solamente para los que vienen de consejos comunitarios io no? entonces ahí hay una discusión. Otro caso, en Chocó ahorita nos pasó que dicen "aquí formalmente estamos haciendo proceso de participación pero no nos aplica porque nosotros todos somos aquí afros e indígenas y nosotros solo nos podemos regir por el protocolo étnico, pero el protocolo sale en 10 meses o sea en marzo del otro año". Entonces ien este tiempo qué hacemos?, ¿no hacemos nada? $\mathrm{O}$, por ejemplo, tenemos 60 consejos comunitarios en el Chocó, iparticipan sesenta consejos comunitarios y una organización de víctimas? Hay particularidades y sutilezas territoriales en las que el protocolo se queda corto y en las que no da líneas ni precisiones de cómo se va a resolver y en los territorios hay angustias porque no hay línea desde Bogotá y desafortunadamente la concentración de decisiones en Bogotá es impresionante o sea cuando tú vas a la regiones y te dicen, eso no lo ha dicho Bogotá, no me lo han mandado de Bogotá entonces no lo hago (Vargas, 20 de junio de 2013, entrevista a María Angélica Gómez, especialista de la Consultoría para los Derechos Humanos y el Desplazamiento Forzado -Codhes-).

En conclusión, aunque se da un avance al crear las reglas de juego para las elecciones con relación al esquema de participación anterior, aún existen vacíos y ambigüedades frente al mecanismo de las elecciones que es necesario aclarar teniendo en cuenta la dinámica y naturaleza de las organizaciones de víctimas, las dinámicas territoriales y la diversidad organizativa al interior de los grupos étnicos.

\subsubsection{Crea unos mecanismos de articulación entre los niveles territoriales}

Para llenar vacíos de representación y articulación entre los comités territoriales y el nacional se desarrollan tres estrategias: primera, las personas elegidas de las ov para los niveles departamental y nacional deben tener un trabajo y estar inscritas en el nivel municipal. Esta forma de elección 
de abajo hacia arriba busca dar mayor legitimidad a quienes ocupan los cargos nacionales. Segunda, el Decreto 4800 de 2011 ordena a los comités departamentales a realizar reuniones con la participación de los municipios de su jurisdicción, con el fin de realizar una evaluación del proceso de implementación de los planes de acción, ${ }^{17}$ así como presentar las necesidades, avances y dificultades de articulación entre entidades estatales y, lo más importante, que en dichas reuniones se aborden las necesidades presupuestales de los respectivos municipios, para que sean tenidas en cuenta en los planes operativos anuales de inversión departamental de la vigencia posterior (Decreto 4800 de 2011). La tercera estrategia consiste en que, el protocolo establece la articulación de responsabilidades institucionales frente al financiamiento de los espacios de participación:

De acuerdo al principio de subsidiariedad, los municipios y distritos que tienen menor capacidad financiera deben ser apoyados por los departamentos y la nación, para cumplir con las garantías para la participación efectiva de las víctimas. Para ello la nación deberá tener en cuenta la categoría del municipio y el porcentaje de la población victimizada. Será obligación de los entes territoriales definir recursos específicos en el Plan de Acción Territorial (PAT), para el funcionamiento de las respectivas Mesas de Participación, indicando claramente el aporte propio y los fondos de cofinanciación solicitados (Resolución 0388 de 10 de mayo de 2013, art. 50).

\subsubsection{Establece sesiones abiertas con cuerpos colegiados}

El protocolo indica que las mesas pueden tener una sesión abierta con el Consejo Municipal, con la Asamblea Departamental y con el Congreso de la República para presentar sus informes y evaluar la aplicación efectiva de la Ley 1448 de 2011.

\subsubsection{Ofrece incentivos para la participación}

Entre los incentivos contemplados por el protocolo están la formación e intercambio de experiencias a nivel nacional e internacional, el acceso a

17 Los municipios deben establecer a los niveles departamental y nacional sus necesidades en términos de oferta institucional para atender y reparar a las víctimas, así como sus demandas presupuestales para que se creen estrategias para hacer reales los principios de concurrencia y subsidiariedad. 
procesos de selección y admisión para la educación superior diferenciales para los líderes de las víctimas involucrados en las Mesas de Participación y la estipulación de becas o créditos condonables, especialmente destinadas a mujeres cabeza de familia, adolescentes, población en condición de discapacidad y grupos étnicos, y la financiación de proyectos para promover y fortalecer la participación de las víctimas.

No obstante las mejoras anteriormente descritas, el nuevo esquema de participación genera unos problemas y desafíos que en la práctica limitan la incidencia que las víctimas pueden llegar a tener sobre decisiones programáticas y presupuestales en los escenarios de participación locales, los cuales se describen a continuación.

\section{Factores estructurales de política pública que obstaculizan la incidencia de las víctimas}

Son varios los aspectos estructurales de los diseños institucionales de la política y de la descentralización que, aun cuando no tengan que ver directamente con la participación, sí la afectan de manera determinante. Entre ellos los siguientes:

\subsection{Débil capacidad institucional, técnica y financiera en lo local}

Uno de los mayores obstáculos consiste en que se crean leyes desde el nivel central como la Ley de Víctimas con un alto nivel de descentralización en su ejecución, pero no se transfiere la capacidad técnica requerida, ni el fortalecimiento de capacidades a los entes territoriales y a los funcionarios sobre temas que en muchos municipios no se manejan, ni los recursos necesarios para su implementación:

Nosotros desde la Federación Colombiana de Municipios, hicimos una encuesta el año pasado a los alcaldes, sobre cuáles eran las leyes que se han transferido a lo local, que generan más capacidad de descentralización y de autonomía y la primera fue la Ley de Víctimas y Restitución de Tierras. Ahora bien, volvemos a la dicotomía que siempre hay en Colombia: ¿por qué entre lo que está escrito y lo que pasa actualmente hay unos abismos tan grandes?... Si bien se diseña una ley en lo central, desde 
la óptica de Bogotá y se transfiere a lo local para que se institucionalice, esta no se transfiere acompañada con una estrategia de capacitación y de fortalecimiento de las capacidades a nivel local, ni de recursos tampoco y esa es la explicación de por qué en el escrito está muy bien y en la práctica no se está dando tan bien, porque los gobiernos locales tienen muchos desafíos en cuanto a recurso humano en esta Ley de Víctimas (Vargas, 23 de junio de 2013, entrevista a Angharad Collado de la Federación Colombiana de Municipios).

El 94\% de los municipios está clasificado en categorías cuatro, cinco y seis, ${ }^{18}$ lo que indica que tienen escasos recursos económicos para su funcionamiento y que dichas administraciones cuentan con equipos muy pequeños para la gestión municipal. A diferencia de las ciudades capitales e intermedias del país, la mayoría de los municipios de Colombia tienen una muy débil capacidad humana, técnica y financiera para implementar los diversos aspectos de la ley que son muy recientes y para los cuales no están preparados como, por ejemplo, la asistencia y reparación, teniendo en cuenta el enfoque diferencial, porque no cuentan con los profesionales necesarios en términos de idoneidad y cantidad para responder a todos los aspectos requeridos y no disponen de recursos propios suficientes para hacerlo.

[...] estamos hablando que los cuerpos de los gobiernos locales en cientos de municipios del país están formados por máximo cuatro o cinco funcionarios, que tienen que asumir todo lo que desde el gobierno central se les da por ejecutar, por lo tanto, no solo tienen que saber de enfoque diferencial y de víctimas, sino que tienen que saber de regalías, tienen que saber de contratos de planes - de emprendimiento, de normatividad agrícola, forestal, ambiental, etc., etc. etc...- y tienen que formar parte de catorce comités similares a los de justicia transicional creados a nivel municipal, entonces uno no puede esperar desde el centro, sabiendo los desafíos que a nivel de capacidades se tiene en lo local, que todo lo que ellos decidan se vaya a ejecutar al pie de la letra y bien. Y no es por falta de voluntad política, es por falta de recurso humano, técnico y económico (Vargas, 23 de junio de 2013, entrevista a Angharad Collado de la Federación Colombiana de Municipios).

18995 municipios son categoría 6 y 49 municipios categorías 4 y 5 (Caballero, Galvis y García, 2012). 
Un ejemplo claro de lo anterior, que puede constituir un eslabón muy importante en la cadena de cosas que tienen que suceder para que los espacios de participación funcionen adecuadamente es el de las secretarías técnicas de las mesas a nivel municipal ejercidas por la personarías, se les transfieren una serie de responsabilidades y tareas, pero no se les fortalece técnicamente para que puedan llevarlas a cabo.

Con la nueva Ley 1448, las personerías son las encargadas de convocar a las OV y ODV, inscribirlas, constatar la existencia de los documentos requeridos para el proceso de inscripción de las organizaciones y con esto prácticamente aprobar cuáles organizaciones participan y cuáles, no, citar las reuniones de la mesa, garantizar el espacio y los aspectos logísticos de las reuniones, apoyar y orientar los planes de trabajo, realizar ejercicios de rendición de cuentas, informar a las mesas sobre los planes, programas y acciones implementados para la reparación a las víctimas, apoyar a las mesas en la elaboración de recomendaciones, observaciones o propuestas, entre otras.

[...] con el papel de las personerías como secretarías técnicas tenemos un primer inconveniente y es la capacidad de liderazgo de las personerías en tanto que tienen una cantidad de facultades que desborda su capacidad presupuestal y humana, entonces tenemos en municipios de categoría seis unas personerías que están en condiciones paupérrimas, que pasan más allá de no tener computador, no tienen ni escritorio, ni silla, ni dónde imprimir, ni dónde escanear. No tienen condiciones para motivar una mesa y no tienen tiempo de sentarse a pensar metodologías, y pedagogías para las reuniones, entonces, son secretarías técnicas sin siquiera una claridad metodológica de cómo guiar esos espacios, de unas personas que tiene muchas iniciativas, propuestas y quejas, pero no está muy claro cómo va a ser la función de facilitador de la procuradurías por que no se han dado los elementos prácticos. Y creo que allí hay un tema que no está resuelto y que no lo resuelve el protocolo, y es que no se ha robustecido a las personerías en la ley ni en el papel (Vargas, 20 de junio de 2013, entrevista a María Angélica Gómez, especialista de la Consultoría para los Derechos Humanos y el Desplazamiento Forzado -Codhes).

El protocolo de participación establece que las alcaldías municipales deben apoyar a la Personería para que esta pueda desarrollar su labor. Pero 
esto en la práctica no es tan factible por varios factores: la ley no es clara al establecer los montos, o pisos y techos que obliguen a los alcaldes a destinar unos fondos mínimos para garantizar esta participación. Entonces, al no estar reglamentado este asunto, el hecho de cuánto dinero destinen pasa por la voluntad política de los alcaldes y por la capacidad financiera de las administraciones municipales.

En síntesis, el problema radica en que se transfiere la política pero no las capacidades, ni la oferta institucional necesaria en lo local para garantizar la implementación de dicha política, sumado al hecho de que el grueso de los recursos económicos para atender a las víctimas tiene una prevalencia de lo sectorial nacional sobre lo territorial, de manera que los recursos destinados por el Estado para atender y reparar a las víctimas llegan en su gran mayoría al nivel central y no a los entes territoriales que, por su debilidad financiera y técnica, no cuentan con los recursos necesarios para responder a las demandas de las poblaciones y no tienen cómo garantizar la oferta estatal en lo local para atender y reparar a las víctimas. Esta presencia diferenciada del Estado en los territorios no solo afecta el desarrollo de la política de reparación a las víctimas, sino que afecta el ejercicio ciudadano y la garantía de los derechos de los colombianos y colombianas en general. La ausencia de institucionalidad, servicios, regulación de los conflictos, justicia, seguridad y paz determina el bajo nivel de incidencia que puede tener la participación de los ciudadanos en la exigencia de sus derechos.

\subsection{Débil articulación entre nación y territorio}

Los principios de articulación, concurrencia, complementariedad y subsidiariedad no son un invento de la Ley de Víctimas, son principios constitucionales que deben regir las políticas; no obstante, el Estado no ha avanzado como se requiere en la concreción de un sistema que establezca claramente la corresponsabilidad y reglamente la forma en que el Estado central apoyará técnica, humana y económicamente a los municipios. Mientras este aspecto no avance, en la práctica será muy difícil implementar la ley y dar respuestas concretas a las reivindicaciones y demandas de las víctimas en lo local, así la Ley de Víctimas establezca en el papel que los departamentos y la nación deben apoyar a los municipios. 
[...] hay algo en lo que no se ha avanzado y es el tema de la corresponsabilidad. No están reglados los temas de subsidiariedad, complementariedad, concurrencia. Si yo, ente territorial categoría seis, solo puedo poner el $8 \%$ del 100\% que tengo que cumplir, pues eso es lo que me comprometo a dar, pero necesito que alguien me dé el resto, el 92\%, y ese alguien es ¿quién?, ¿el departamento? y ¿cuánto me va a dar?, ¿el 20\%, el 30\%, el 50\%? Y de lo que falte ia quién le toca? A la nación. Pero no hay una regla clara, ni un sistema específico que me diga a mí que, si bien las alcaldías tienen una importancia de jalonar recursos, el 100\% de los recursos no sale de ahí porque no les alcanza el presupuesto. Tenemos un 90\% de entes territoriales pobres en el país y donde están muchas de las víctimas y no se les puede cargar a ellos la responsabilidad ciento por ciento de jalonar" (Vargas, 20 de junio de 2013, entrevista a María Angélica Gómez, especialista de la Consultoría para los Derechos Humanos y el Desplazamiento Forzado -Codhes-).

$\mathrm{Al}$ respecto, la Corte Constitucional ha señalado la necesidad de crear un sistema de corresponsabilidad ante las eminentes fallas de articulación entre la nación y los entes territoriales (Auto 383 de 2010). Frente a esta exigencia se han generado algunos avances. De una parte, el Decreto 4800 de 2011 establece como uno de los sub-comités técnicos del SNARIV el de 'coordinación nación y territorio' en el que participan el Ministerio de Hacienda, el Ministerio del Interior, la Unidad de Víctimas y el Departamento Nacional de Planeación -DNP-. Este subcomité debe promover la coordinación nación-territorio, orientar a las entidades territoriales en la formulación de sus planes de acción y establecer los lineamientos para la efectiva implementación de las medidas de atención, asistencia y reparación de las víctimas. Pero este proceso no avanza tan rápido como lo requiere la ley y aún no se ha reglamentado un sistema claro de articulación. Además, persiste la ausencia de un mecanismo, escenario o proceso que permita el diálogo o la participación de estas entidades con los alcaldes y los gobernadores como actores principales de dicha articulación.

La Unidad de Víctimas tiene como una de sus subdirecciones la de 'coordinación nación -territorio' desde la que debe proponer un plan de acción para facilitar dicha coordinación. En este sentido, la subdirección ha diseñado instrumentos como el índice de capacidad territorial con el cual focalizó la oferta en lo local, lanzó un programa de cofinanciación en el 
que invitó a los departamentos a presentarse con proyectos para reparar a las víctimas y a solicitar la cofinanciación por parte de la Unidad y apoyó a varias entidades territoriales, brindando de manera temporal y transitoria la ayuda humanitaria de emergencia. Finalmente, asesoró a diversos entes territoriales en la elaboración de sus PAT, para que establezcan los recursos que poseen y los que necesitan para poner en marcha sus planes.

A pesar de estos esfuerzos, el problema estriba en que la articulación 'nación-territorio' no arranca y no tiene en cuenta a todos los entes territoriales sino solo a algunos, ${ }^{19}$ además, que aún no está reglamentada, que sigue siendo discrecional de las entidades sectoriales del orden nacional qué tipo de complementariedad económica, técnica y humana van a brindar a los municipios.

No es una tarea fácil coordinar y articular 37 entidades que hacen parte del SNARIV y a su vez garantizar su articulación con las entidades territoriales sub-nacionales. Menos aun cuando cada entidad tiene plena discrecionalidad para emprender dicha articulación con los territorios como bien le parezca y en total ausencia de un mecanismo o espacio que convoque a los alcaldes y gobernadores, como principales autoridades de los gobiernos locales, en la creación de los lineamientos de política pública que se deciden en el nivel central y que son transferidos para que sean implementados por ellos en lo local.

Este esquema de política pública, que parte del supuesto de que no hay rozamiento institucional y reúne a una gran cantidad de agencias en un sistema tan complejo y disperso, no es nuevo y es más que evidente su fracaso, por lo menos en garantizar los derechos de propiedad rural (ver por ejemplo, el esquema planteado por la Ley 160 de 1994 que creó el Sistema Nacional de Reforma Agraria y Desarrollo Rural Campesino). Pero el Estado insiste en repetir estos esquemas en medio de procesos ${ }^{20}$ que, por estar en el marco de la justicia transicional, deberían atender el problema de una manera más expedita, concreta, masiva y rápida.

19 Por ejemplo, lo que ocurrió con el programa de cofinanciación: de los 68 proyectos que presentaron los departamentos para solicitar cofinanciación a la Unidad para reparar a las víctimas, solo se aprobaron ocho (Unidad para la Atención..., s.f.).

20 Las agencias del Estado o del gobierno central no han realizado una evaluación seria sobre el impacto de las políticas que se montan sobre sistemas que demandan tal nivel de articulación institucional. 


\subsection{La violencia: ser líder o representante de las víctimas en este país es una profesión de alto riesgo}

Uno de los retos más grandes para la participación de las víctimas, en particular, y para la aplicación de la Ley de Reparación y Restitución de Tierras, en general, es la persistencia del conflicto armado en muchas zonas del país y el peligro adicional que representa para los líderes de las víctimas de convertirse en una amenaza para los grupos armados y otros actores de los poderes políticos locales, debido a sus justas reclamaciones de ser reparados y restituidos.

La participación de las víctimas se ha visto gravemente afectada por las acciones de los poderes locales resistentes a los procesos de reparación de las víctimas. En varias zonas los poderes que tuvieron el mando en la era de la parapolítica se han reestructurado y continúan teniendo dominio y poder de decisión e injerencia en las dinámicas económicas y políticas de las comunidades (Encuestas de los analistas regionales de la Defensoría del Pueblo, 2013), obstaculizando las iniciativas de reparación, promoviendo ejércitos anti-restitución de tierras, desplegando procesos de estigmatización contra los líderes y lideresas sociales que promueven procesos de exigencia de sus derechos y asesinando a los que participan en procesos de restitución o a los defensores de derechos humanos. ${ }^{21}$

La violencia que persiste contra ellos obstaculiza a todas luces su ejercicio político y el logro de sus reivindicaciones en dos vías: primera, la violencia letal y no letal, busca intimidar, desestructurar los procesos organizativos y echar para atrás las demandas de restitución y segunda, la decisión de micro-focalizar las zonas en las que se van a implementar aspectos importantes de la política, como la restitución de tierras, que está directamente relacionada con las condiciones de seguridad existentes en los territorios. De este modo, si la inseguridad persiste, no van a poder ser restituidos, porque el proceso sencillamente no arrancará en sus territorios.

Uno de los aspectos más graves consiste en que no existe ni siquiera un conteo oficial de cuántos líderes, defensores y población víctima han sido asesinados. Este es un problema que el Estado tiene que poner como primer

21 Las bandas emergentes denominadas 'bacrim' tienen injerencia en la vida electoral y política de los municipios limitando las iniciativas de los gobiernos locales en pro de las (Arrázola, 2013). 
punto de la agenda. Por citar unas cifras de la magnitud de la violencia contra los defensores de derechos humanos en lo que va corrido del año 2013, el informe "Héroes Anónimos" del programa Somos Defensores registra un total de 153 agresiones individuales contra defensores(as), discriminados en 86 amenazas, 37 asesinatos, 21 atentados, 6 detenciones arbitrarias, 2 casos de uso arbitrario del sistema penal y 2 de robo de información (Programa no gubernamental..., 2013).

Uno de los aspectos centrales de los homicidios contra líderes es su vinculación en muchos casos con procesos de reclamaciones de tierras despojadas o su solicitud de restitución de tierras. En este sentido, la Defensoría del Pueblo señaló que "entre 2006 y 2011 ocurrieron al menos 71 asesinatos de líderes de procesos de restitución de tierras" (Reina impunidad..., 2012). Ahora bien, la violencia contra la población desplazada que no ejerce liderazgo, pero que tiene esta condición ha sido alarmante "entre 2007 y marzo de 2010 se produjeron 1.499 homicidios de personas en condición de desplazamiento" (Naciones Unidas, 2010), sin nombrar las múltiples amenazas y violaciones a DDHH que generan, en no pocas ocasiones, nuevos desplazamientos forzados. Si bien La Unidad de Protección ha reforzado los esquemas de seguridad para los líderes de víctimas y defensores de derechos humanos, reactivando la ruta de protección con dos tipos de medidas: blandas, relacionadas con la dotación de dispositivos tales como avanteles, chalecos anti-balas, etc., y duras, relacionadas con la dotación de escoltas, camionetas blindadas y salidas temporales del país, estas son en extremo demoradas y no han sido efectivas ni siquiera para evitar el homicidio de seis líderes que participaban en las mesas transitorias de participación convocadas por la Unidad de Víctimas, tal y como lo señala Alfonso Castillo, Dirigente Nacional de ANDAS:

Uno de los elementos que creo hay que destacar como absolutamente lesivo, no solo para el proceso de mesas sino en general para la participación de las víctimas es la ausencia total de garantías para le prevención y la protección. En este sentido hay que señalar que durante todo el proceso de discusión del protocolo fueron asesinados seis dirigentes de las mesas de transición departamentales. pero, además de eso, el mecanismo establecido por el gobierno y la Unidad Nacional de Protección para brindar garantías de protección a las personas amenazadas ha sido supremamente 
lento y creo que no ha brindado las garantías de protección conforme a las respectivas condiciones de las personas que las demandan. Hay unas medidas estándar que no necesariamente aplican a la condición de todos y eso creo que vulnera. Ese es un gravísimo problema en un país que sigue teniendo conflicto armado, que tiene ejércitos anti-restitución, grupos paramilitares que siguen operando tal cual y ahora, como podemos señalarlo con claridad, la misma Unidad de Protección dedicada al espionaje de los líderes con una serie de medidas tecnológicas, seguimientos, etc., de tal suerte que no se brindan esas garantías para la participación (Vargas, 11 de julio de 2013, entrevista a Alfonso Castillo, directivo de la Asociación Nacional de Ayuda Solidaria ANDAS).

Pareciera que la participación tiene mayores garantías de seguridad en los espacios de diálogo con el Estado a nivel nacional, pero no ocurre lo mismo en los escenarios locales de participación, en muchos casos los líderes y las lideresas desconfían de la autonomía de las autoridades y entidades locales, de sus relaciones con poderes locales mafiosos y de la capacidad de injerencia que aún tienen los grupos armados al margen de la ley en muchas zonas del país en las que tuvieron lugar casos emblemáticos de despojo y abandono de tierras y que actualmente están en la mira frente a los procesos de reparación y restitución.

\subsection{Frágil cultura política alrededor del tema de la participación}

Otro de los aspectos estructurales que limita la participación tiene que ver con la cultura política existente en los territorios por parte de los funcionarios, las víctimas y la sociedad civil, sobre la importancia y alcance que esta puede llegar a tener. La frágil cultura política se evidencia en dos aspectos: primero, en el desconocimiento que existe sobre la normatividad que obliga y reglamenta la promoción de la participación; dicho desconocimiento no solo afecta a las víctimas, sino también a los funcionarios encargados de implementar y garantizar la participación. En este sentido, los líderes señalan la necesidad de fortalecer las capacidades de los funcionarios en los contextos locales tanto de los instrumentos normativos que determinan responsabilidades para la participación, como de herramientas pedagógicas y metodológicas para acompañar el trabajo de las víctimas. 
[...] muchas de las administraciones municipales desconocen sus obligaciones de apoyar económicamente los aspectos necesarios para la participación; los personeros se han quejado porque necesitan herramientas para direccionar metodológicamente el trabajo en las mesas (Vargas, 20 de junio de 2013, entrevista a María Angélica Gómez, especialista de la Consultoría para los Derechos Humanos y el Desplazamiento Forzado -Codhes) [...] Por ejemplo, esta ley trata conceptos muy nuevos en Colombia, como es el tratamiento desde el enfoque diferencial a las víctimas y estamos hablando de que en los gobiernos locales no había gente que supiese o estuviese capacitada sobre lo que es e implica el enfoque diferencial de atención a víctimas (Vargas, 23 de junio de 2013, entrevista a Angharad Collado de la Federación Colombiana de Municipio).

Ese desconocimiento se explica en parte por la persistencia de un imaginario bastante extendido en los funcionarios del Estado y en la sociedad civil, de que la participación no es un tema prioritario en la política pública de reparación de las víctimas y de un prejuicio revelado por procesos anteriores, en que la participación es un ejercicio desgastante para las personas, altamente costoso y poco efectivo al momento de acceder a las conquistas por parte del Estado.

[...] existe un prejuicio de que la participación no es tan importante. Por poner un ejemplo, para unos, lo más importante es la restitución de tierras y vivienda, entonces, lo que a mí me importa como gobierno local es coordinar más con la política nacional en estos temas, pero la participación. Humm... dejémoslo en un segundo plano (Vargas, 23 de junio de 2013, entrevista a Bárbara González de la Corporación Viva la Ciudadanía).

Esta frágil cultura política alrededor del tema de la participación de las víctimas también afecta su capacidad de incidencia porque, al desconocer los derechos y mecanismos con los que cuentan, se reduce su capacidad para exigir a las entidades el cumplimiento de los escenarios, las condiciones, las garantías y los incentivos para la participación, reduce la posibilidad de que nuevos simpatizantes se sumen al movimiento de víctimas, e invisibiliza sus acciones en escenarios formales del Estado, limitando el alcance que pueden llegar a tener. 


\section{Conclusiones: impactos de estos problemas estructurales de la política pública sobre la participación}

Los problemas estructurales descritos anteriormente dan cuenta de una política pública marcada por la dispersión institucional y normativa, en un gobierno multinivel (local, departamental y nacional) desarticulado. El gobierno propendió por la creación de un sistema de implementación de la política de atención y reparación a víctimas altamente descentralizado, pero no estableció un sistema claro de corresponsabilidad entre la nación y los entes territoriales que permitiera la transferencia de los recursos y las capacidades técnicas a los entes territoriales que en lo local no cuentan con la capacidad económica, técnica y fiscal para responder a las demandas de las víctimas y garantizar sus derechos.

La forma en que está concebida la política pública de atención y reparación a las víctimas de la violencia limita la incidencia que estas buscan tener en el esquema de participación creado por el Estado porque existe una brecha entre los escenarios de planeación en lo local y aquellos de decisión en el nivel nacional. Si bien con la Ley de Víctimas se crearon unas estrategias y mecanismos para posibilitar una mayor articulación entre los espacios de participación a nivel municipal, departamental y nacional, aún persiste una prevalencia de lo sectorial nacional sobre lo territorial en lo programático y lo presupuestal que le dificulta a los entes territoriales la toma de decisiones, en tanto que las víctimas dependen y requieren de una altísima capacidad de interlocución y articulación con una gran cantidad de agencias del nivel nacional encargadas en el sistema de atención y reparación a las víctimas.

Estos problemas estructurales tienen varios impactos sobre la participación de las víctimas, entre ellos, los siguientes:

- Las reglas de juego establecidas generan problemas de acción colectiva entre los participantes porque no responden a las dinámicas organizativas de las víctimas en lo local y provocan una mayor atomización de sus organizaciones quienes se enfrentan en una competencia por acceder a los cupos en los escenarios de participación. El Estado no ha centrado su estrategia en la creación de mecanismos, espacios y procesos orientados al fortalecimiento de las confianzas, de los vínculos 
y del diálogo entre las organizaciones de víctimas, ni en la promoción de su unidad en torno a un gran movimiento, como actor político reconocido enfocado en la construcción de agendas programáticas con mayor capacidad y fuerza de interlocución y representación.

- La participación tal y como está concebida reduce y homogeniza a los actores en una categoría asociada a la victimización y al daño, e invisibiliza la categoría de sujeto social y político.

- Se canaliza y encauza la indignación a través de mecanismos institucionales: las organizaciones y sus representantes invierten sus energías, tiempo y recursos en mantener vivas sus organizaciones y en competir entre ellas para participar de los escenarios, más que en la puesta en marcha de repertorios de movilización disruptivos que les permitan convertirse en una amenaza para el Estado, o en un movimiento capaz de generar presión para alcanzar sus reclamos. Las organizaciones están respondiendo al llamado del Estado para encauzar sus demandas a través de las vías institucionales y los resultados mínimos de la implementación de la política dan cuenta de que no están logrando sus reivindicaciones mediante dichos mecanismos.

- Se generan altos costos para las víctimas: participar en un esquema como el propuesto por el Estado es altamente costoso porque demanda de las víctimas tiempo y recursos que muchas de ellas no están en condiciones de dar. Para un grueso de esta población, que se encuentra por debajo de la línea de pobreza y que está expuesta a múltiples condiciones de exclusión social, el dilema está entre el logro de su sustento diario y la destinación del tiempo exigido para la participación. Además de lo anterior, la participación de las víctimas genera riesgos para ellos y sus familias dada la estigmatización social, la persecución contra ellas por su ejercicio político y la violencia propia del conflicto que persiste en las regiones.

- Algunas experiencias muestran que la participación local es efectiva especialmente cuando se orienta a asuntos prioritarios para los actores involucrados con capacidad de decisión y a la vez no tienen muchos costos para otros grupos. En este sentido, parte del éxito o de la capacidad de incidencia depende del grado de fortaleza de la infraestructura local para la participación. Sin embargo, el caso señalado aquí es diferente, porque la capacidad de respuesta frente a las demandas de los 
actores que participan en lo local depende en gran medida de fuerzas y agencias del orden nacional y de su posibilidad de articulación con lo local.

En este orden de ideas, para que se genere incidencia es necesario que se desarrollen y fortalezcan las capacidades de decisión en lo local y se definan mecanismos claros y expeditos de articulación de las entidades sectoriales del orden nacional con las entidades territoriales. En este sentido, es clave que el protocolo de participación aborde este punto central, porque es el que determina el lugar donde se toman las decisiones gruesas de política pública y de presupuesto sobre el desarrollo de la política de atención y reparación a las víctimas.

Los problemas estructurales descritos anteriormente y sus efectos sobre la participación de las víctimas ponen sobre la mesa algunos de los diseños de política pública que deben ser revisados y reformulados si se quiere promover una verdadera incidencia política y el fortalecimiento de su capacidad de interlocución como un sujeto político con mayor capacidad para lograr sus reivindicaciones.

\section{Referencias}

\section{Bibliográficas}

Arrázola, M. R. (2013, 2 de junio). Se abre capítulo bacrimpolítica. El Espectador. Recuperado de http://www.elespectador.com/noticias/judicial/articulo-425485-seabre-capitulo-bacrimpolitica

Caballero, C., Galvis, D. y García, M. V. (2012). Intervención ad hoc en municipios colombianos de acuerdo con indicadores sociales. Bogotá: FESCOL.

Comisión de seguimiento a la política pública sobre desplazamiento forzado (2008, 31 de enero). Proceso Nacional de Verificación de los Derechos de la Población Desplazada, Primer informe a la Corte Constitucional. Bogotá. Recuperado de http:// www.internaldisplacement.org/8025708F004CE90B/(httpDocuments)/740A 794DA6EBAD25C12575A500454329/\$file/I+Informe+Comisi\%C3\%B3n+ de+Seguimiento+-+I+ENV+(enero+31+-+08).pdf

De Sousa Santos, B. (1998). Participatory Budgeting in Porto Alegre: Toward a Redistributive Democracy. Politics \& Society, 4. 
Finot, I. (2002). Descentralización y participación en América Latina: Una mirada desde la economía (2002). Revista de la Cepal, 78, 139-149.

Goldfrank, B. y Schneider, A. (2006), Competitive institution building: the PT and Participatory Busgesting in Rio Grande do Sul. Latin American Politics and Society, 48(3), 1-31.

Gutiérrez, F. (2007). Participación ciudadana y pobreza en Colombia. Bogotá: Departamento Nacional de Planeación -DNP-.

Hernández Bonivento, J. A. (2009). Problemas institucionales de la participación ciudadana: análisis conceptual y aplicación al caso colombiano. Caracas: Centro Latinoamericano de Administración para el Desarrollo. Recuperado de http://www.clad.org/ documentos/otros-documentos/problemas-institucionales-de-la-participacionciudadana-analisis-conceptual-y-aplicacion-al-caso-colombiano/view

Hevia, F. (2007). Participación ciudadana institucionalizada y despolitización: análisis crítico de los marcos legales de la participación en América Latina, Centro de Estudos da Metrópole/Centro Brasileiro de Análise e Planejamento, CEM/BRBRAP. Recuperado de http://www.opalc.org/web

Isaac, T. y Patrick, H. (2003). Decentralization, Democracy and Development: The People's Campaign for Decentralized Planning in Kerala. En A. Fung y E. Olin Wright, (eds.). Deepening Democracy: Institutional Innovations in Empowered Participatory Governance. Londres: Verso.

Líppez de Castro, S. (2010). ¿En qué proporción de las decisiones de política e inversión local en Colombia podrían participar los ciudadanos? Hacia la operacionalización de la autonomía territorial. Papel Político, 15(1).

Massal, J. (2010, mayo/ agosto). Democracia participativa. Desafíos y desencantos en el siglo XXI. Análisis Político, 23(69), 79-91.

Mascareno, C. (2008). Descentralización y democracia en América Latina: ¿Una relación directa? Maryland: The University of Maryland College Park, Working paper 23.

Montecinos, E. (2005, agosto). Los estudios de descentralización en América Latina: una revisión sobre el estado actual de la temática. EURE, XXXI(93), 73-78.

Naciones Unidas (2010). Informe de la Alta Comisionada de las Naciones Unidas para los Derechos Humanos sobre la Situación de los DDHH en Colombia. Recuperado de https://docs.google.com/viewer? $\mathrm{a}=\mathrm{v} \mathcal{E}$ pid $=$ explorerEchrome=trueEsrcid=0Bx Wyp4XphucrYjZjMzNmN2EtNzFjZC00NjNjLWE1MDktZjMxMDc1MTdjM TNiGhl=enGpli=1

Pedraza, B. y Restrepo, D. (2009). Las entidades territoriales en la realización de derechos de la población desplazada. Limitaciones y posibilidades frente al estado de cosas inconstitucional. Bogotá: Codhes. 
Programa de las Naciones Unidas Para el Desarrollo -PNUD- (2004). La democracia en América Latina: hacia una democracia de ciudadanas y ciudadanos. Nueva York: Abril. Programa no gubernamental Somos Defensores (2013). Informe Héroes Anónimos 2013. Recuperado de http://somosdefensores.org/index.php/extensions/68ultimo-informe-siaddhh/416-informe-semestral-2013-siaddhh-heroes-anonimos SNARIV (2013). Informe del sistema nacional de atención y reparación integral a las víctimas a las comisiones primeras de Senado y Cámara. Bogotá: Ministerio del Interior.

Unidad para la Atención y Reparación Integral a las Víctimas (s.f.). Proyectos beneficiados a través del Mecanismo de Cofinanciación. Recuperado de (http://www.unidadvictimas.gov.co/index.php/en/79-noticias/574-mecanismos-de-coofinancianion).

Uprimny, R. (2004). Justicia constitucional y desplazamiento forzado en Colombia. En Memorias del Seminario Nacional de Derecho de Ciudadanía y Población en Situación de Desplazamiento. Bogotá: Códice.

Vargas Reina, J. (2012). Diseños institucionales que promueven la participación pero limitan la incidencia política de las organizaciones de población desplazada. Análisis Político, 76, 41-58.

Vargas Reina, J. (2012). Factores que condicionan la incidencia y la acción colectiva de OPDS - el caso de Soacha - (tesis de maestría). Instituto de Estudios Políticos y Relaciones Internacionales -IEPRI-, Universidad Nacional de Colombia, Bogotá.

\section{Periodísticas}

Reina impunidad en asesinatos de líderes de tierras (2012, 9 de abril). Revista Semana. Recuperado de http://www.semana.com/nacion/articulo/reina-impunidadasesinatos-lideres-tierras/256131-3

\section{Leyes, decretos y resoluciones}

Departamento Administrativo de la Función Pública (2011). Decreto 4802. Bogotá. Corte Constitucional (1998). Sentencia C-126. Bogotá.

Corte Constitucional (2004). Sentencia T-025. Bogotá.

Corte Constitucional (2010). Auto 383. Bogotá.

Corte Constitucional (2009). Auto 008. Bogotá.

Corte Constitucional (2009). Sentencia C-175. Bogotá.

Congreso de la República (1993). Ley 89. Bogotá.

Congreso de la República (1993). Ley 101. Bogotá.

Congreso de la República (1997). Ley 387. Bogotá.

Congreso de la República (2011). Ley 1448. Bogotá. 
Congreso de la República, Cámara de Representantes (2006). Proyecto de Ley 282. Bogotá

Ministerio de Hacienda y Crédito Público. Exposición de Motivos. Por el cual se dictan normas en materia financiera, de seguros, del mercado de valores y otras disposiciones. Recuperado de http://www.superfinanciera.gov.co/NormativaFinanciera/exposicionrf2008.pdf, consultado el 12 de noviembre de 2013.

Ministerio de Justicia y del Derecho (2011). Decreto 4800. Bogotá.

Presidencia de la República de Colombia (2005). Decreto 250. Bogotá.

Presidencia de la República. (2011). Decreto 4800. Bogotá.

Presidencia de la República de Colombia (2012). Decreto 0790. Bogotá.

Unidad de Atención y Reparación Integral para las Víctimas (2013, 10 de mayo). Resolución 0388. Bogotá. 
